\title{
Small business management in Madhya Pradesh: Factors influencing their failure
}

\author{
Varun Yadav ${ }^{1^{*}}$ \\ Assistant Professor, Amaltas Institute of Medical Science, Dewas, Madhya Pradesh, India \\ *Corresponding Author: Varun Yadav \\ Email: varuny.indore09@gmail.com
}

\begin{abstract}
In the course of the most recent decade, examination into big business improvement has developed in light of the monstrous disappointment of various mechanical and financial changes which has invigorated incredible reaction from the private areas, subsequently the need to enhance advancement measures with supportive of dynamic strategies to accomplish the ideal objective. Little scope venture has been the foundation of the Madhya Pradesh economy since the vigorous of privatization, the same number of individuals at this point don't rely upon the legislature for them to make due aside from in not many circumstances.
\end{abstract}

Keywords: SME, Management \& Failure.

\section{Introduction}

Little and medium endeavors (SMEs) assume a significant part in monetary improvement in each nation, remembering for African nations. Writing on big business improvement recommends that in both progressed economies and nonindustrial nations SMEs contribute on normal $60 \%$ of complete conventional work in the assembling area. Hence, for African economies, the commitment of the SME area to openings for work is much more significant and records for around $75 \%$ of complete work in assembling.

The Development Agency has set up various projects to support a similar scale business, for example, furnishing them with the vital climate by facilitating the regulatory plan and making to have simple admittance to back and evening the odds. These endeavors have been arranged into three advancement columns specifically, limit, access and working climate. Regardless of these endeavors the greater part of the little scope undertakings are working in a descending winding with the majority of them shutting down their organizations and returning to their old methods of working together.

A business is a dangerous endeavor and caution that the odds of entrepreneurs making it past the five-year point are extremely thin. Recent investigation into independent venture advancement has likewise demonstrated that the pace of disappointment of little scope organizations in nonindustrial nations is higher than in the created world.

It was from this foundation that this examination was attempted to determine the variables that impact the little scope business inability to prevail past five years in the serious business climate in Madhya Pradesh.

\section{Concept of business failure}

The disappointment of any business negatively affects various partners, for example, loss of the mean of creation and appropriation of merchandise and ventures by the network, occupations by workers, incomes from charges by the legislature and loss of speculation capital. ${ }^{1}$ The effect of business disappointment is obliterating to the owner(s) and the network everywhere and requires more consideration.
Researchers by and large concur in their meanings of business disappointment as discontinuance of the business. Nonetheless, the meaning of business disappointment actually vary regarding the explanations behind discontinuance. The broadest definition is business mortality because of insolvency.

As per Ropega, ${ }^{2}$ it's critical to get why and how business fall flat since disappointment is certifiably not an unexpected function yet a unique cycle and it additionally assists with understanding the birthplace of disappointment and how it very well may be forestalled in future.

\section{SME Classification}

The classification of SMEs for this study was based on the MSME Policy. According to the policy, firms are classified by the number of full time employees engaged and the sales turnover. Firms which employ up to 10 full-time workers and have the sales are referred to as micro enterprises. Those employing between 11 and 50 workers and the sales turnover between Within the MSME sector, manufacturing activities account for $41 \%$ while trading account for $49 \%$. Services accounted for only $10 \%$.

\section{Factors influencing failure of SMEs}

A ton of examination has been finished by various creators on the components that impact little scope business disappointment and achievement. Story ${ }^{3}$ considers the developing little firm by a Categorization joining three parts to be specific, the beginning assets of the business visionary (s), the firm and the methodology. The ramifications of the above assertion is that less quickly developing, nodevelopment or bombing firms may have some proper qualities in the business visionary, firm or methodology territories, yet it is just where every one of the three join that the quick development firm is found.

The aftereffects of past investigations zeroed in on the birth, development and passing of little firms, have introduced some standardizing "rules and regulations" exercises for little firm. ${ }^{1,3}$

As indicated by Philip ${ }^{4}$ the elements affecting SMEs can be characterized into the accompanying classifications; 
a business person Characteristics, for example the board and skill of items and client administrations and markets; the method of working together; collaboration and the quality of SMEs as far as the capacity to procure advances from the money related foundations, for example, banks.

Moreover, an examination led by Nkonoki, ${ }^{5}$ credited the disappointment of little scope business because of the absence of schooling which he portrayed as a vital segment of human resources required for business achievement. He contended that instruction and preparing gives the premise to scholarly advancement required by business people in business to be fruitful. Also, they furnish the business visionaries with certainty to manage customers. Consequently, instructed business visionaries indicated all the more encouraging outcomes as far as how their business is getting along.

It is constantly contended that business possession isn't a scholarly action rather business is an open door for the less scholastically effective to acquire big time salaries.

Disappointment variables can be arranged into outside and inward factors. ${ }^{6}$ Instances of outer components are admittance to fund, helpless economic situations, insufficient staff, and absence of institutional help, collaboration and systems administration. These variables are adequately perceived while the inward factors, for example, absence of methodology and vision, low instructive level and deficient social capital through not adequately perceived.

From the viewpoint of the budgetary establishments, SME portion is viewed as a vital need for the banks and productive business prospect which gives a significant occasion to strategically pitching. ${ }^{7}$

Writing has indicated various miniature and large scale factors ruining the banks from connecting independent companies. Miniature elements ted factors, for example, the absence of satisfactory data and security just as their generally family-claimed structures are seen to obstructions to the banks. Moreover, Macroeconomic elements, business guideline, the lawful and authoritative climate, the absence of a more proactive government mentality towards the fragment, a few territories of prudential guideline and some bank-explicit variables are likewise seen to adversely influence the SME loaning market in separately. ${ }^{8}$

The writing has abided much into understanding the idea of SMEs, their characterization and how they sway on the economy both in creating and created countries. It has additionally tended to a few factors that impact the achievement of little scope business in different nations. The variables, for example, the absence of sufficient market data and insurance just as their to a great extent family-possessed structures, business guideline, the legitimate and legally binding climate, and the absence of a more proactive government mentality towards the section where investigated to see how they impact SMEs disappointment. Consequently this investigation was an endeavor to decide the factor(s) which are urgent to independent venture accomplishment past five years with regards to climate.

\section{Methodology}

This examination paper in the result of the thesis, gathered essential information from the mix of overview polls and semi-organized meetings of key sources. Overview polls were utilized to empower singular disappointment components of private companies to be inspected and semiorganized meetings empowered as to examination successfully the reactions from the surveys.

As an inspecting strategy, we embraced purposive examining strategies to create the essential information since it includes picking respondents whose perspectives are pertinent, significant and of incentive to the exploration (Jankowicz, 2005). This methodology was proper for this investigation in view of need dependable information which makes it hard to concentrate independent ventures.

For the example size, Saunders et al (2003) contended that for measurable examination, a base number of thirty (30) gives a valuable dependable guideline. Nonetheless, for this examination we picked an example size of 100 surveys and led 5 semi-organized meetings with key sources on a coordinated, eye to eye premise. Information preparing was performed through dominate and stata. The investigation was directed for the time of eight (8) months.

From the outcomes it tends to be suggested that more men are occupied with little scope business undertaking in light of absence of work openings and that men must take care of the families back home or they hazard inundated in the pattern of neediness.

As to levels of training, the examination uncovered that $48 \%$ are testament holders who are the lion's share, $25 \%$ confirmations, and $16 \%$ have no capabilities, and $11 \%$ of them have degrees and no PhD and bosses holders.

Out of 100 questionnaires distributed, only 95 were collected which represents $95 \%$ respondents. This percentage $(95 \%)$ of the sample was sufficient and significant for analysing and identifying key failure factors for small businesses.

\section{Research Findings}

Table 1: Gender distribution

\begin{tabular}{|l|c|c|c|}
\hline S. No. & Gender & No. & Percentage \\
\hline 1 & Male & 73 & 73 \\
\hline 2 & Female & 27 & 27 \\
\hline
\end{tabular}

The profile of respondents showed that $73 \%$ of the respondents were male and $27 \%$ female.

Table 2: Types of businesses

\begin{tabular}{|l|l|c|c|}
\hline S. No. & Types of Businesses & No. & Percentage \\
\hline 1 & Marketers & 05 & 05 \\
\hline 2 & Talk time booths & 21 & 21 \\
\hline 3 & Grocery owners & 32 & 32 \\
\hline 4 & $\begin{array}{l}\text { Second hand clothes } \\
\text { traders }\end{array}$ & 42 & 42 \\
\hline
\end{tabular}


When respondents were asked about the type of business they are engaged in, the results showed that $5 \%$ of the respondents are Marketers, $21 \%$ talk time booths, $32 \%$ grocery owners and $42 \%$ of them are second hand clothes traders as shown below.

Table 3: Performance of businesses in the last five years

\begin{tabular}{|l|c|c|c|}
\hline S. No. & $\begin{array}{c}\text { Performance of } \\
\text { businesses in the last } \\
\text { five years }\end{array}$ & No. & Percentage \\
\hline 1 & Poor & 42 & $42 \%$ \\
\hline 2 & Good & 32 & $32 \%$ \\
\hline 3 & Excellent & 21 & $21 \%$ \\
\hline 4 & Not Sure & 03 & $03 \%$ \\
\hline
\end{tabular}

On performance of businesses in the last five years, the results of the study revealed that majority representing $42 \%$ indicated that the business has been very poor and only $31 \%$ seemingly agreed to the fact the business environment has been good owing to the fact they have had a business plan from the onset in the last five years. Only $21.1 \%$ stated that they have had an excellent business environment. However the remaining respondents representing 5.3\% expressed ignorance as they did not know whether they have had an improvement or reduction in the running of their business.

Table 4: Factors influencing failure

\begin{tabular}{|l|l|c|c|}
\hline S. No. & $\begin{array}{l}\text { Factors influencing } \\
\text { failure }\end{array}$ & No. & Percentage \\
\hline 1 & $\begin{array}{l}\text { Lack of Market } \\
\text { Information }\end{array}$ & 42 & $42 \%$ \\
\hline 2 & Financial Constraints & 21 & $21 \%$ \\
\hline 3 & High Taxes & 21 & $21 \%$ \\
\hline 4 & Lack of Collateral & 16 & $16 \%$ \\
\hline
\end{tabular}

The respondents were asked to state the factors leading to the failure of small medium enterprise (SMEs). The information shows that most of them were of the view that the major factor was the lack of market information that represented 40 respondents giving rise to $42.1 \%$. $21 \%$ representing 20 respondents of those interviewed had a similar feeling that financial constraints and the wide range of high taxes imposed the local authorities and the central government played a part in demotivating the SMEs in conducting business. It can be seen that the remaining $16 \%$ clearly disagreed with the other group and stated that what causes failure of small businesses is lack of collateral or proper legal documentation that would eventually ease the accessibility of loans for theme to survive in heavily competed business environment.

\section{Discussion}

Little scope ventures have been viewed as the foundation of the Madhya Pradesh economy since the coming of privatization, the same number of individuals at this point don't rely upon the legislature for them to make due aside from in scarcely any circumstances. Ongoing examination into private company advancement has additionally indicated that the pace of disappointment of little scope organizations in non-industrial nations is higher than in the created world. As per Ropega, ${ }^{2}$ getting why and how business fizzle is significant on the grounds that disappointment is anything but an abrupt function yet a powerful cycle and it likewise assists with understanding the cause of disappointment and how it very well may be forestalled in future, thus the requirement for this examination.

The principle point of this exploration was to investigate and distinguish the key disappointment factors for independent ventures. We examined a wide range of individuals that managed different organizations that can be delegated little. Most of the entrepreneurs were guys and the rest females which shows that there are more men occupied with little scope business undertaking on the grounds that the absence of work openings and the men must take care of the families back home or they hazard inundated in the pattern of neediness. Concerning the degree of schooling, larger part of the entrepreneurs are endorsement holders and followed by confirmation holders and an enormous number of them had none. This shows that the degree of training is low for them to peruse and comprehend the changing economic situations. As indicated by Nkonoki, ${ }^{5}$ schooling and preparing gives the premise to scholarly improvement required by business people in business to be fruitful.

Innovative exercises are impacted by various elements relying upon the climate. The consequences of the examination uncovered that that a large portion of the respondents were particularly affected by their own drive as it a verifiable truth M.P. towns' financial action as has been gradually developing when contrasted with different towns combined with the predominant pace of destitution. Consequently, as a method of endurance individuals have taken advantage of lucky breaks and left on their own drive. The other inspiring components is the departure of individuals looking for work has become a defining moment for those that return and those that have stayed to fire up an independent company that target improving the status center of house hold food security. In such manner, it is critical to show that paying little mind to the different spurring factors into any type of business, the exhibition has been commonly poor because of inability to comprehend the rationale in beginning the business. Business execution is essentially identified with the intention behind the set up of a business and the more sure inspiration of the business person the more probable the business will develop.

On the disappointment factors for independent companies, the investigation demonstrated that the major or key factor is absence of market data concerning how to get to field-tested strategies and when and how to get the right data that identifies with business enrollment which is because of no or low level as recommended by Haase and Franco. ${ }^{6}$ Besides, the exploration uncovered that separated from the absence of market data, the private companies are obviously influenced by the predominant budgetary imperatives and high duties forced on them by the focal and 
the nearby specialists through what they named as pointless tolls that occupied their everyday tasks of a business in the focal business region. As indicated by Akabueze, [9], it would appear to be sensible to expect that independent companies would develop and prosper, yet the pace of business disappointment keeps on expanding in light of the deterrents influencing business execution which include: absence of budgetary assets and absence of the board insight. This impediment in getting money consequently prompts deficient skillful faculty that can't in the long run to control costs.

In any case, the issue of security is a critical factor for entrepreneurs. The discoveries of the investigation show that, organizations bomb because of karma of security needed to get to the credits to help their organizations. This is in accordance with Kuzilwa ${ }^{10}$ who recommended that guarantee requirement and regulatory methods are main considerations thwarting the accomplishment of private ventures as they oblige them from acquiring assets from loaning organizations. The vast majority of the entrepreneurs don't have important property that can be utilized to make sure about an advance and where property exists they have no title deeds.

\section{Conclusions}

The investigation has likewise uncovered that there is a positive connection between the quantity of long periods of activities and the exhibition of the business or that the more one remains in business the higher the likelihood that he/she would return the benefits and extend the business limbs in different types of variety.

\section{Source of Funding}

None.

\section{Conflict of Interest}

The authors declare no conflict of interest.

\section{References}

1. Ihua UB. SMEs Key Failure-Factors: A Comparison between the United Kingdom and Nigeria. J Soc Sci. 2009;18(3):199207.

2. Ropega J. The Reasons and Symptoms of Failure in SME. 2011;17(4): 476-83.

3. Storey DJ. Understanding the small business sector, Thomson, 1994.

4. Phillip M. Factors affecting business success of small and medium enterprise (SMEs). APJRBM. 2011;1(2):SN 2229.

5. Nkonoki E. what are the factors Limiting the Success and Growth of Small Businesses in Tanzania. An Empirical Study on Small Business Growth. Acada university press, Helsinki, 2010.

6. Franco M, Haase H. Failure factors in small and medium-sized enterprises: qualitative study from an attributional perspective. Int Entrepreneurship Manag J. 2010; 6(4):503-21

7. Briscoe A, Hempel M. (1996). Regional Collaboration in Small Business Promotion. Gaborone. Botswana.

8. Peters - Scheepers B. (2005). Awakening the SMME giant through productivity. Productivity SA: Inspiring a Competitive South Africa, 2015;31 (2):18.

9. Akabueze B. Financing small and medium enterprises (SMEs): The Small and Medium Industries Equity Investment Scheme (SMIEIS) Option. Lagos. Nigeria, 2002.

10. Kizilwa J. The Role of Credit for Small Business Success A Study of the National Entrepreneurship Development Fund in Tanzania. J Entrepreneurship. 2005;4(2):131-61.

How to cite this article: Yadav V. Small business management in Madhya Pradesh: Factors influencing their failure. J Manag Res Anal. 2020;7(4):147-50. 